\title{
Letter to Editor: Recommendations for safer management of holding OSCE during COVID-19 outbreak
}

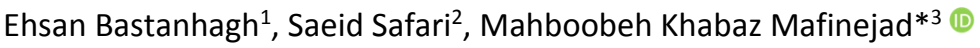 \\ Received: 5 Jun 2020 \\ Published: 17 Nov 2020
}

Conflicts of Interest: None declared

Funding: None

*This work has been published under CC BY-NC-SA 1.0 license.

Copyright $($ Iran University of Medical Sciences

Cite this article as: Bastanhagh E, Safari S, Khabaz Mafinejad M. Letter to Editor: Recommendations for safer management of holding OSCE during COVID-19 outbreak. Med J Islam Repub Iran. 2020 (17 Nov);34:156. https://doi.org/10.47176/mjiri.34.156

\section{Letter to editor,}

Coronavirus disease 2019 (COVID-19) is the third coronavirus that has emerged in the past 2 decades, causing a path in making practical changes in medical education. Educational planners and teachers are confronted with different educational challenges, including canceling all face-toface sessions, postponing exams, and delaying educational activities in clinical settings. Moreover, conducting high stake assessments such as objective structured clinical examination (OSCE) is difficult during different phases of curriculum $(1,2)$. The OSCE is one of the popular clinical skills examinations and has been used for residents and medical students' assessment across a broad range of medical disciplines (3-5). During the COVID-19 pandemic, we are faced with many obstacles for minimizing risks and protecting the safety of medical students, faculties, standardized patients (SPs) and personnel for planning and conducting OSCE. Based on our experiences in the Clinical Skills Center at Tehran University of Medical Sciences (TUMS), some recommendations for conducting OSCE in safer exam settings during the COVID-19 outbreak are presented:

1. Setting up OSCE with minimum but standard stations.

2. Limit the number of participants and students as much as possible without any group gathering.

3. Allocating a place for registration at entrance, preferably outside the building.

4. Body temperature screening and taking brief history, on arrival, about encountering patients, family members or friends with COVID-19 or travel in the last weeks
5. Designing and implementing the exam in the Clinical Skills Center instead of hospitals or clinics.

6. Sharing the instruction and map of the building a day before by social media for facilitating access.

7. Preparing all protections for safety such as sanitizers, masks, gowns, gloves, and face-shields for all participants, personnel, SPs, and faculties.

8. Performing social distancing in each part of OSCE and choosing larger rooms ( 6 feet apart except for physical examination)

9. Cleaning all equipment and manikins after each stop in the stations.

10. Using manikins and simulators for assessing physical exam skills of students instead of SPs as much as possible

11. Using a hand sanitizer before and after each station.

12. Placing air condition with enough negative pressure in the stations and rooms

13. Using cascade method instead of circuit for less contact between participants

14. Using video conference instead of physical attendance for standard patients when possible in the history taking stations.

15. Using digital scoring instead of paper-based questionnaire methods.

16. Using high quality cameras to record student performance at stations and score live or for subsequent evaluations by evaluators.

As we navigate through this crisis, seeking ways to enhance our teaching and assessment experience while preserving the routine that we have already established with

Corresponding author: Dr Mahboobeh Khabaz Mafinejad, m-mafinejad@tums.ac.ir

1. Department of Anesthesiology and Critical Care, Clinical Skills Center, Tehran University of Medical Sciences, Tehran, Iran

2. Functional Neurosurgery Research Center, Shohada Tajrish Neurosurgical Comprehensive Center of Excellence, Shahid Beheshti University of Medical Sciences, Tehran, Iran

3. Education Development Center (EDC), Department of Medical Education, Health Professions Education Research Center, Tehran University of Medical Sciences, Tehran, Iran 
our students is necessary. We hope the recommendations provided can help make OSCE tests safer in the event of a Covid-19 pandemic.

\section{Conflict of Interests}

The authors declare that they have no competing interests.

\section{References}

1.Wu F, Zhao S, Yu B, Chen YM, Wang W, Song ZG, et al. A new coronavirus associated with human respiratory disease in China. Nature. 2020;579(7798):265-9.

2.Boursicot K, Kemp S, Ong TH, Wijaya L, Goh SH, Freeman K, et al. Conducting a high-stakes OSCE in a COVID-19 environment. MedEdPublish. 2020;9.

3.Bani-issa W, Al Tamimi M, Fakhry R, Al Tawil H. Experiences of nursing students and examiners with the Objective Structured Clinical Examination method in physical assessment education: A mixed methods study. Nurse Educ Pract. 2019;35:83-9.

4.Heal C, D’Souza K, Banks J, Malau-Aduli BS, Turner R, Smith $\mathrm{J}$, et al. A snapshot of current Objective Structured Clinical Examination (OSCE) practice at Australian medical schools. Med Teach. 2019;41(4):441-7.

5.Harden RM. Revisiting 'assessment of clinical competence using an objective structured clinical examination (OSCE)'. Med Educ. 2016;50(4):376-9. 